\title{
Morphological Variation of Limnonectes blythii in West Sumatera, Indonesia
}

\author{
Wince Hendri ${ }^{1}$, Djong Hon Tjong ${ }^{2}$, Dahelmi $^{3}$, and Dewi Imelda Roesma ${ }^{4}$ \\ ${ }^{1}$ Department of Biology, Faculty of Education and Pedagogy, Bung Hatta University Padang, West \\ ${ }^{2,3,4}$ Department of Biology, Faculty of Mathematics and Natural Science, Andalas University. Padang, \\ West Sumatera, Indonesia
}

\begin{abstract}
:
This study aimed to analyze the morphological variations of Limnonectes blythii in West Sumatra by usingmorphometric in Genetics and Cytology Laboratory, Department of Biology, Faculty of Mathematics and Natural Sciences, Andalas University, Padang. The sample of this research was collected directly in Malampah (Nature Reserves Malampah) West Pangian II (Nature Reserve Pangian II)Sijunjung Harau (Harau Nature Reserve) Payakumbuh in February until Mai 2015. The results showed that there is genetic variation in morphology of the population L. blythii in Malampah and Pangian II as the first cluster with a population in Harau. The kinship between populations in Pangian II and Malampah as the second cluster is closer to the population at second subcluster with Harau population and have the more distant kinship of the population L. blythii in Pangian II. It was concluded that 12 morphological characters show differentiation significant $(\mathrm{p} \geq 0.05)$ of the population, while the population of Harau and Pangian II showed significant differentiation as many as 10 characters $(32.2 \%)$, Between population differentiation Harau with Malampah show as much as 8 characters $(25.8 \%)$, and between population Malampah with Pangian II show 7 (22.58\%)differentiated character. L. blythii experiences morphological variations between populations in the character of the head length and eyelid length. This study requires molecular analysis to clarify the relationships among L. blythii to preserve the information of this frogs as an export commodity.
\end{abstract}

Keywords: morphometry, diversity, Limnonectes

\section{Introduction}

L. blythii is one of a large amphibian that often used to capture and export as a source of income for residents in West Sumatra. Lately, this species is rarely found in their habitat because of the limitation of its population. It is caused by the uncontrolled human habit in arresting and the use of pesticides that can kill tadpoles and froglet which are growing and the destruction of habitat [1]-[2].

Indonesia is one of the largest diversity centers in the world, not only in terms of natural resources but also in terms of its type of endemic level. $16 \%$ of the world's amphibians and reptiles or more than 1100 species are found in Indonesia, This species is usually found in high air humidity areas, for example, the zone around a river. Furthermore, the height of a region also affects the diversity of this kind of amphibian [3]
The frog can be used to measure environmental; problem. It can be seen from the color of his skin, the way of life, and even defection or loss of certain species of frogs which indicated damage to the environment [4].

L. blythii is a complex species which actually consists of several species but morphologically, it may indistinguishable because of that, it is hard to differentiate the relationships Limnonectes existed in West Sumatra and Southeast Asia. There were some researchers about amphibians in West Sumatra including L. blythii both aspects of taxonomy, evolution, ecology, and genetics of the specific type. As has been done by [5]-[6]-[7][8]-[9] however the evolutionary relationships among its family to interpret biogeographic classification is very need to be analyzed. $L$. blythii population has been decreased. It caused by the conservation assessment efforts and the right 
protection has never been done, In the future, the pressure frog population will continue and it may be endangered species.

Diversity assessment can be done by morphological markers. Morphometry of data can be explained by the differences and similarities between populations rather than molecular markers. The population growth that resulted in changes in population distribution, the grouping of certain types on areas that rarely disturbed by the man so that evolutionary changes in the composition and structure of the population [7][10].

The morphological variations of $L$. blythii species found in Sumatra are not well recognizing. To make it clear, it needs to be analyzed by the morphological diversity of different populations in Sumatra between its populations and also their interaction gene that influenced by their environment. Based on this issue, a research titled "Morphological Variation L. blythii giant frog in West Sumatra is importation to be conducted:" This study is expected to formulate about genetic diversity, habitats, the study of molecular evolution in the preservation of L. blythii in the future.

\section{Material and Method}

The sample this research were collected on February to Mei 2015, in the outskirts of the rivers nature reserve area, Malampah (Nature Reserve Malampah), Pangian II (Pangian II Nature Reserve), Lima Puluh Kota (Reserves Nature Harau). Morphological characters measurement refers to the method of [8]. Measurement data were analyzed by using NTSYS program Ver. 2.0.2i to see Euclidian distance and result in venogram and principal component analysis (PCA) with 3.1 MVSP programs. Morphometric analysis performed in phenotype by measuring morphological characters. Morphometric measurements were done by using a digital caliper with accuracy up to $0.05 \mathrm{~mm}$. Materials used are alcohol $70 \%$ and $10 \%$ formalin.

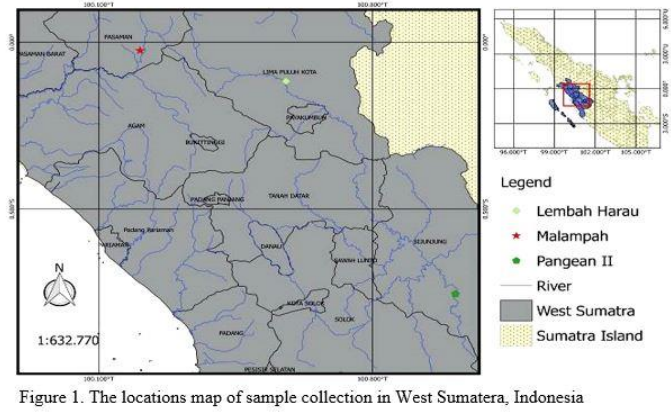

Collecting the samples carried out directly along the flow of the river at night from 7 p.m to 12 a.m at midnight. The Limnonectes was caught directly by the help of a flashlight in order to make them blind and do not jump. Samples were gotten and inserted into the bag, labeled and taken to a laboratory for identification and preservation for further observation. Anesthesia was conducted by injecting alcohol $70 \%$ of the back of the head up into the brain. Inoculation with alcohol in order to make the frog becomes weak than that of $70 \%$ alcohol was also injected into the abdomen so that the sample identical conditions while still alive. After the sample was getting weaker, the next step was preservation. Preservation was done by setting the samples body in the good position. The front legs should form an angle of 90, the rear legs folded so that the heel met behind the vent. All fingers were stretched well so that membranes can be clearly seen like swimming. This will facilitate the measurement. Labeling was the next step in conducting this research. Every sample should be given a label which was not easy to remove by chemistry substance especially alcohol, label 2B pencil or Indian ink had been used. Samples which had been labeled arranged in a tray of tissue that has been moistened with $10 \%$ formalin for one week so that the position of the sample body becomes stiff and could not be changed. Then the sample was transferred into a collection bottle to be immersed in alcohol 90\%. Then, fixation process was completed and morphometry measurement may be done.

Sample measurement refers to Heyer et al. (1994) and Djong et al. (2007). The character was measured 31 characters (Figure 2). Measurement of morphological aspects of amphibian may be done to adult stage of an animal. This measurement includes some the size of the animal (in $\mathrm{mm}$ ). Then, the samples were given formalin $10 \%$ of the issued and washed with clean water. After drying it, the samples were placed 
over the surgical basin morphology measurements with 31 characters measured as shown in Figure 1

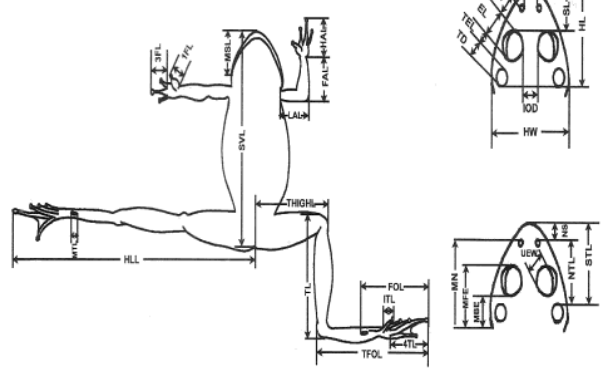

Figure 1: Measurement of morphology Amphibians [11]

Caption: SVL: length body (the distance between the cloaca until the tip of the snout), HL: long head (the distance between the end of the lower jaw valentine snout), HW: width head (the distance between the angle of the jaw), STL: distance from the muzzle until the tympanum, MSL: long snout (the distance between the front edge of the eye socket valentine snout), NS: distance from nose to muzzle, SL: distance from the eye until muzzle, NTL: distance from nose up tympanum, EN: distance from eyes up nose, TEL: distance from the eye until tympanum, TD: diameter tympanum (distance longest circumference tympanum), ETLl: distance from the mandible up nose, MFE: distance from the mandible to eye home, MBE: distance from the mandible to eye rear, IN: distance inter nares (distance between the nostrils), EL: eye diameter (distance longest circumference of the eye), IOD: distance inter orbital (the distance between the two orbital eye), UEW: long eyelid, HAL: long manus until digit, LAL: long branchium, FAL: long antebranchium, HLL: long leg rear (the distance between the distal end tibio-fibula to the end of the fourth finger), THIGHL: the length of the femur (the distance between the cloaca distal femur), TL: long tibia (the distance between the distal end of the tibia to proximal), TFOL: length from metatarsus up fingertips to four legs rear, FOL: length of tarsus up finger to four legs rear, F3L: long finger to the three foot forward, 1FL: long finger first foot forward, 4TL: long finger to four legs rear, MTL: metatarsal length tubercular inside, 1TL: first leg length rear

\section{Data analysis}

After measuring of the number of specimens of each species, morphometry results data were analyzed to obtain fenogram (family tree) as a group. This method was done by using taksimetri namely: a). Determination of Operational Taxonomic Units (STO) for morphometric analysis. b). Selection of characters measured were the main morphological characters. c). All data morphometry in ratio with standard length parameter (PS) and log-transformed with 10 to get normality of data. d). Determination of Euclidian distance analysis using the technique UPGMA (unweighted pair-group method using arithmetic averages) with NTSYS program. (Numerical Taxonomy and Multivariate Analysis System) $2.02 \mathrm{i}$ version. PA analysis was used to determine the pattern of population differentiation of Limonectes morphometry of some areas. The analyzed data was data that has been rationale with morphometry standard length and transformed to $\log -10$. Furthermore, the data were processed by using the program to obtain a plot MVSP 3.1. The Character of overall population differentiation Morphometry use Kruskal-Wallis test. It was conducted to identify the characters that show significant differentiation of the population Two-Test direction with the MannWhitney $U$ Test was used to know the morphometric differentiation between two distinct populations of species of frogs found.

\section{Results And Discussion}

From the research that has been done, the number of individuals obtained from each population was shown in the following table:

Table 1: The number of sample acquisition for each location.

\begin{tabular}{ll}
\hline Location & Number of Sample \\
\hline Malampah & 12 \\
Harau & 12 \\
Pangian II & 16 \\
\hline Total & 40 \\
\hline
\end{tabular}

Limnonectes Blytii could be found on edge of the water. They are sitting on the sandy grass about 10 $\mathrm{cm}$ above the surface, although in very small amounts. Sometimes this species of frog found in the mainland area of approximately 1 meter from the water's edge. The average value, standard deviation, minimum and maximum values and the results of the Mann-Whitney test the entire population L. blythii can be seen in Appendix 1 . These species have some characteristics. They are the body is large, the head is flat, smooth snout and triangular shapes. Tip of the snout can be 
pointed or blunt. The lore is slightly concave, lore and tilt are down the cheek, there is a narrow groove between the eye and upper jaw bone. Timpani supra crease running from the back of the eye through the top of the eardrum toward the axilla in the form of an arch. Among the backs of both eyes, there is a groove that is unclear. The tympanic membrane is clearly visible. On the upper eyelid back there is a pimple. At the front, there is a jaw pair bony prominence, with an oval tongue thick and forked. On the front leg, there is a small sphere-shaped finger, the third finger sequentially relatively longer than the first, fourth and second fingers. On the medial side of the second and third fingers are ridges charity, 1 lateral side of the second finger does not thrive, while on the lateral side of the third finger has the ridge. Metacarpal tubercles are large and oval. Full swimming webbed hind limbs, toes end up with small discs. Swimming membrane between the fourth and fifth toes high corresponds with the third subarticular and slightly concave. A sequentially fourth toe is longer than the third finger, fifth, second and first finger. The lateral side of the fifth finger and the medial tarsal skin folds (creases tarsal) were unclear or non-existent. Medial tarsal tubercles large and elongated, while the subarticular tubercles round or oval. The skin is smooth and it has color is different for part of a body. At the top of the head and back are brown light gray and dark gray to black with black or brown spots. Moreover, the Loreal line is stretching from the nose to the eye was never found. The lines between the eyes are not clear. Sign the letter $\mathrm{W}$ on the dorsal aspect that exists between the two front limbs are sometimes seen clearly, it is sometimes not clear. The back line that stretches from parts of the ear to the rectum was never found. Then, there is a pigmented ventral surface of the head. Next, their lips are often dark blotch or vertical. At the front of the upper arm leg, lore is irregular. In the dorsal part of the thigh are irregular, while at the back there is an irregular spot. On the back of the calf and leg treads is lore. The lower surface of the hind limbs, pale yellow or pale orange or brown spots should. males do not have a voice sac.

3.1. Character differentiation entire population.

The results of the analysis of morphological characters L. blythii population by using KruskalWalls can be seen in the following Table 2:
Table 2: Results of Kruskal-Wallis test with significant character for all the population $(\mathrm{N}=$ 40) L. blythii:

\begin{tabular}{|c|c|c|c|}
\hline Character & $X^{2}$ & $\mathrm{df}$ & $\mathrm{P}$ \\
\hline SVL & 12.538 & 2 & $0.002 *$ \\
\hline $\mathrm{HL}$ & 16.746 & 2 & $0.000^{*}$ \\
\hline HW & 1.418 & 2 & $0.492^{\mathrm{ns}}$ \\
\hline STL & 6.437 & 2 & $0.040 *$ \\
\hline MSL & 14.503 & 2 & $0.001 *$ \\
\hline SL & 6.240 & 2 & $0.044 *$ \\
\hline SL & 3.260 & 2 & $0.196^{\mathrm{ns}}$ \\
\hline NTL & 1.241 & 2 & $0.538^{\mathrm{ns}}$ \\
\hline EN & 1.834 & 2 & $0.400^{\mathrm{ns}}$ \\
\hline TEL & 9.420 & 2 & $0.009^{*}$ \\
\hline TD & 0.657 & 2 & $0.720^{\mathrm{ns}}$ \\
\hline ETL & 3.595 & 2 & $0.166^{\mathrm{ns}}$ \\
\hline MFE & 5.150 & 2 & $0.076^{\mathrm{ns}}$ \\
\hline MBE & 5.687 & 2 & $0.058^{\mathrm{ns}}$ \\
\hline IN & 7.145 & 2 & $0.028^{*}$ \\
\hline EL & 11.139 & 2 & $0.004 *$ \\
\hline IOD & 10.937 & 2 & $0.004^{*}$ \\
\hline UEW & 30.997 & 2 & $0.000 *$ \\
\hline HAL & 0.651 & 2 & $0.722^{\mathrm{ns}}$ \\
\hline LAL & 21.247 & 2 & $0.000^{*}$ \\
\hline FAL & 4.016 & 2 & $0.134^{\mathrm{ns}}$ \\
\hline HLL & 1.901 & 2 & $0.387^{\mathrm{ns}}$ \\
\hline THIGHL & 8.048 & 2 & $0.018^{*}$ \\
\hline $\mathrm{TL}$ & 3.611 & 2 & $0.164^{\mathrm{ns}}$ \\
\hline TFOL & 1.586 & 2 & $0.452^{\mathrm{ns}}$ \\
\hline FOL & 1.828 & 2 & $0.401^{\mathrm{ns}}$ \\
\hline F3L & 0.563 & 2 & $0.755^{\mathrm{ns}}$ \\
\hline $1 \mathrm{FL}$ & 4.753 & 2 & $0.093^{\mathrm{ns}}$ \\
\hline $4 \mathrm{TL}$ & 2.455 & 2 & $0.293^{\mathrm{ns}}$ \\
\hline MTL & 0.346 & 2 & $0.841^{\mathrm{ns}}$ \\
\hline ITL & 1.743 & 2 & $0.418^{\mathrm{ns}}$ \\
\hline
\end{tabular}

From Table 2 above shows the character turns 12 significant differentiation $(\mathrm{p} \geq 0005)$ the character SVL (body length), HL (long head), STL (distance muzzle tympanum), MSL (long snout), NS (distance nose to snout), TEL (the distance from the eye to tympanum), IN (distance inter nares), EL (diameter of the eye), IOD (distance inter-orbital), UEW (the length of the eyelids), LAL (length branchiaum) and Thigh (femur length). Variation in the morphology of a species is a response to changes in the physical environment where the species. With the differentiation and the high variation observed in all populations, it may be an indication that the 
occurrence of speciation. The more differentiation found in morphological characters, the higher the variability of its species.

3.2. Morphology Character differentiation between Two Populations

The results of the analysis between the two populations by using the Mann-Whitney $U$ test can be seen in the following table:

differentiation between populations Harau with Malampah show that character is measured shows differentiation of 8 characters $(25.8 \%)$ character is a character SVL (body length, HL (long head), TEL (distance from the eyes of the tympanum ), MSL (long snout), NS (distance from the nose to mouth), LAL (length branchium) and 1FL (first finger length forefoot). Description: significance $p$ $\geq 0.005, \mathrm{~ns}=$ non-significant, $*=$ significance, character information can be seen on the working method. Based on the analysis of the MannWhitney test showed that the population L. blythii between Harau and Pangian II showed differentiation of the highest character that measured shows significant.

Table 3: Results of the analysis of the Mann-Whitney Test between populations L. blythii

\begin{tabular}{|c|c|c|c|c|c|c|}
\hline \multirow[t]{2}{*}{ Character } & \multicolumn{2}{|c|}{ Harau-Malampah } & \multicolumn{3}{|c|}{ Malampah-Pangian II } & Harau-Pangian II \\
\hline & $\mathrm{U}$ & $\mathrm{P}$ & $\mathrm{U}$ & $\mathrm{P}$ & $\bar{U}$ & $\mathrm{P}$ \\
\hline$\overline{\text { SVL }}$ & 19.5 & $0 *$ & 90.5 & $0.8^{\text {ns }}$ & 29.0 & $0 *$ \\
\hline HL & 8.0 & $0 *$ & 53.5 & $0.05^{*}$ & 36.0 & $0^{*}$ \\
\hline HW & 49.5 & 0.18 & 95.5 & $0.98^{\text {ns }}$ & 79.5 & $0.44^{\text {ns }}$ \\
\hline STL & 30.0 & $0.01 *$ & 64.0 & $0.13^{\text {ns }}$ & 69.5 & $0.21^{\mathrm{ns}}$ \\
\hline MSL & 13.5 & $0 *$ & 37.5 & $0.01 *$ & 58.0 & $\mathbf{0 . 0 8}^{\text {ns }}$ \\
\hline NS & 37.50 & 0.05* & 73.0 & $0.28^{\text {ns }}$ & 50.0 & $0 *$ \\
\hline $\mathbf{S L}$ & 42.5 & $0.09^{\text {ns }}$ & 74.0 & $0.30^{\text {ns }}$ & 74.50 & $0.31^{\text {ns }}$ \\
\hline NTL & 55.0 & $0.32^{\mathrm{ns}}$ & 84.0 & $0.57^{\text {ns }}$ & 79.5 & $0.44^{\mathrm{ns}}$ \\
\hline EN & 50.5 & $0.21^{\text {ns }}$ & 95.0 & $0.96^{\text {ns }}$ & 72.5 & $0.27^{\text {ns }}$ \\
\hline TEL & 48.5 & $0.17^{\text {ns }}$ & 61.5 & $0.11^{\text {ns }}$ & 31.0 & $0 *$ \\
\hline TD & 62.5 & $0.58^{\text {ns }}$ & 94.5 & $0.94^{\text {ns }}$ & 78.5 & $0.41^{\mathrm{ns}}$ \\
\hline ETL & 53.5 & $0.28^{\mathrm{ns}}$ & 57.50 & $0.070^{\mathrm{ns}}$ & 77.0 & $0.37^{\mathrm{ns}}$ \\
\hline MFE & 46.500 & $0.140^{\text {ns }}$ & 47.50 & $0.02 *$ & 85.0 & $0.61^{\text {ns }}$ \\
\hline MBE & 62.50 .0 & $0.58^{\mathrm{ns}}$ & 55.0 & $0.06^{\mathrm{ns}}$ & 51.5 & $0.04 *$ \\
\hline IN & 45.5 & $0.12^{\mathrm{ns}}$ & 37.0 & $0.01 *$ & 83.5 & $0.55^{\text {ns }}$ \\
\hline EL & 39.500 & $0.060^{\text {ns }}$ & 58.500 & $0.080^{n s}$ & 29.000 & $0 *$ \\
\hline IOD & 44.50 & $0.11^{\mathrm{ns}}$ & 56.0 & $0.06^{\mathrm{ns}}$ & 28.5 & $0^{*}$ \\
\hline UEW & 23.0 & $0.01 *$ & 0.5 & $0^{*}$ & $0^{*}$ & $0 *$ \\
\hline HAL & 69.0 & $0.86^{\mathrm{ns}}$ & 82.5 & $0.52^{\mathrm{ns}}$ & 81.0 & $0.48^{\text {ns }}$ \\
\hline LAL & 7.0 & $0 *$ & 95.5 & $0.98^{\text {ns }}$ & 5.5 & $0^{*}$ \\
\hline FAL & 62.500 & $0.580^{\text {ns }}$ & 48.500 & $0.030^{*}$ & 78.000 & $0.400^{\mathrm{ns}}$ \\
\hline HLL & 54.500 & $0.300^{\text {ns }}$ & 87.000 & $0.670^{n s}$ & 69.000 & $0.210^{\mathrm{ns}}$ \\
\hline THIGHL & 43.500 & $0.100^{\text {ns }}$ & 50.500 & $0.030^{*}$ & 47.000 & $0.020^{*}$ \\
\hline TL & 41.000 & $0.070^{\text {ns }}$ & 80.000 & $0.450{ }^{\mathrm{ns}}$ & 69.000 & $0.200 \mathrm{~ns}$ \\
\hline TFOL & 53.500 & $0.28^{\mathrm{ns}}$ & 93.5 & $0.910^{\mathrm{ns}}$ & 72.50 & $\mathbf{0 . 2 7 0}^{\mathrm{ns}}$ \\
\hline FOL & 49.500 & $0.19^{\text {ns }}$ & 80.0 & $0.460^{\mathrm{ns}}$ & 80.0 & $0.460^{\mathrm{ns}}$ \\
\hline F3L & 68.0 & $0.82^{\mathrm{ns}}$ & 85.0 & $0.610^{\mathrm{ns}}$ & 81.0 & $\mathbf{0 . 4 8 0}^{\mathrm{ns}}$ \\
\hline 1FL & 34.5 & $0 *$ & 94.0 & $0.930{ }^{n s}$ & 60.0 & $0.090^{\mathrm{ns}}$ \\
\hline $4 \mathrm{TL}$ & 57.5 & $0.4^{\mathrm{ns}}$ & 88.0 & $0.71^{\mathrm{ns}}$ & 60.5 & $0.10^{\mathrm{ns}}$ \\
\hline MTL & 70.5 & $\mathbf{0 . 9 3}^{\text {ns }}$ & 86.0 & $0.64^{\text {ns }}$ & 85.0 & $0.61^{\text {ns }}$ \\
\hline
\end{tabular}




\begin{tabular}{|l|l|l|l|l|l|l|}
\hline $\mathbf{1 T L}$ & 61.5 & $\mathbf{0 . 5 4}$ & 87.5 & $\mathbf{0 . 6 9}^{\text {ns }}$ & 65.5 & $\mathbf{0 . 1 5}^{\text {ns }}$ \\
\hline
\end{tabular}

difference $(\mathrm{p} \geq 0.05) 10$ characters $(32.2 \%)$, ie the character SVL (body length), HL (length head), NS (distance nose and eyes), TEL (distance eye with tympanum), MBE (distance from the mandible to back of the eye, EL (diameter of the eye), IOD (distance inter orbital), UEW (the length of the eyelids), HLL ( long leg) and THIGHL (femur length). Analysis of Differentiation between populations Malampah with Pangian II show 7 (22:58\%) significant character is the character HL (long head), MSL (long snout), MFE (distance from mandible to eyes front), IN (distance inter nares), UEW (length eyelid), FAL (length ante branchium) and THIGH (femur length). This shows the number of different morphological characters as real as the population Malampah with Harau. There was no significant difference on the HL (Long head) of each population were observed. This shows the different patterns of adaptation to environmental changes. Differences morphological variation between Pangian II is lower than Malampah if it is compared between Harau and Pangian II.

The analysis is based on the PCA plot looks population $L$. blythii distinctly separate but overlap as shown in the figure below:

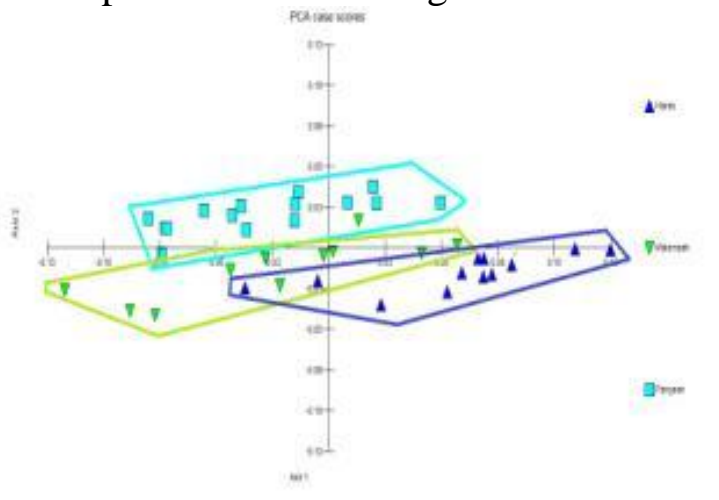

Figure 3: Plot ordinate Principle Analysis (PCA) of the entire population.

Plot ordinate Principle Analysis (PCA) of the entire population were observed shows the population of $L$. blythii contained in Malampah shows the variation near Harau population, but it was closer to Pangian II, whereas between Pangian II population shows a greater distance with Harau, although the geographical, this area is closed. It caused by several different environmental factors such as temperature, food, habitat or the plantation of palm rubber in this area and pesticides.

\subsection{Grouping L. blythii between populations}

Grouping L. blythii between populations can be seen in Figure 4 below:

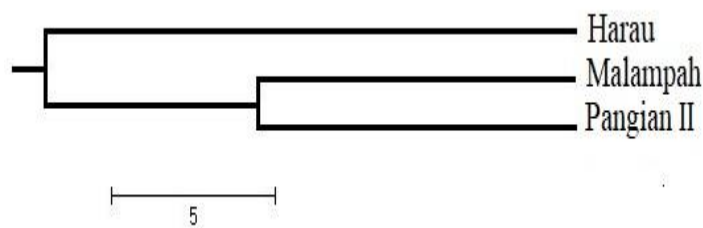

Figure 4: Dendrogram between populations based on morphological characters L. blythii with UPGMA in West Sumatra.

Figure 4. shows that Limnonects Blythii can be grouped into two clusters, namely clusters Harau and Pangian II with Malampah on second cluster. This explains the close kinship between Malampah and Pangian II population compared to the population Harau. This can occur due to the structure of the vegetation in the Nature Malampah and Pangian II still classified as a tropical rainforest with vegetation types and environmental conditions. It means that existence of oil palm plantations can disrupt natural habitats. Therefore, close relationship clusters compared with conditions Harau nature reserve unspoiled. Distance clusters can be seen in the Table 4:

Table 4: Distance Euklidian L. blythii between populations of different areas in West Sumatra

\begin{tabular}{|l|l|l|l|}
\hline Location & Harau & Malampah & Pangian II \\
\hline Harau & 0,00 & - & - \\
\hline Malampah & 9,255 & 0,00 & - \\
\hline Pangian II & 9,674 & 2,600 & 0,00 \\
\hline
\end{tabular}

From Table 4 Euklidian visible distance between L. blythii Pangian II population with Harau (9674) further than the Malampah $(2,600)$. Euclidean distance between Malampah with Harau population is relatively close (9255) compared with the population Pangian II. This is consistent with the analysis in accordance with the MannWhitney U Test which explained that kinship closest L. blythii species is between populations Malampah with Pangian II, but the kinship between Harau closer Malampah population 
compared to the population Pangian II and Harau. It means that the same species which living in different ecological pressure conditions, tend to show a high divergence of character, especially the character of phenotype and may also be a genetic character (Moyle and Cech, 2000).

\subsection{Discussion}

Grouping the adjacent population but has a high differentiation among populations with Pangian II and Harau Harau with Malampah, but a low variation between populations Malampah with Pangian II. It can be caused by fragmentation or destruction of habitats or vegetation changes. [5], suggest that current views of species diversity of the forest frogs of this floristically and geologically complex region are serious underestimates. Application of molecular techniques to other widespread 'species' is likely to expose cooccurring taxa that, once separated by molecular genetics, will also be seen. According to (Das and Has 2005), a lot of character differentiation in the population, the higher the variations of these species and can further demonstrate evolutionary process toward speciation. [13], changes in forest vegetation types due to disruption, fragmentation and pollution and damage to the habitat of amphibians can lead to changes in temperature. [14], also said that changes in vegetation types can increase the temperature and the humidity due to the opening of the tree canopy that can affect the rate of growth in the population of amphibians, causing changes in body size.

Barrier physical environment such as the difference in temperature and food sources will affect the adaptation of morphological characters. Factor gene flow of species difficult to perform across on different populations are more likely to have a difference in phenotype and genotype. $L$. blythii in the Nature Malampah and Pangian II the second cluster with a population that is contained in the Nature Harau the first cluster with kinship most nearby is between $L$. blythii population Nature Reserve Malampah with population Sijunjung compared with L. blythii population Harau on the second cluster and differentiation high morphology between each population $L$. blythii. It can be caused by several factors such as their geographical isolation, ecological causes, and gene flow is obstructed so that there is the existence of genetic variation in morphology. Safeguard these frogs as a wealth of diversity, commodity exports and livelihoods needs to be done, because this large-sized frog existence began to decrease.

Given the separation of populations L. blythii with distant proximity, but the frog population has decreased, there should be efforts to maintain its sustainability. The frog can be used to measure environmental; problem. It can be seen from the color of his skin, the way of life, and even defection or loss of certain species of frogs which indicated damage of environment [5]. Changes of this nature in our views of species diversity and distribution are likely to affect our views of historical geographical relationships, to stimulate ecological investigations and to have implications for conservation. Conservation efforts can be done in-situ and ex-situ. In-situ conservation, conducted by rationalizing the arrest and restoration of the reservation area. Ex-situ conservation, including maintenance of the population, which includes the domestication and management of genes with regard to several factors, such as population size, inbreeding, and genetic drift rate.

\section{Conclusions and Recommendations}

Based on research that has been done, the characters that show differentiation significant $(\mathrm{p} \geq$ 0005) on L. blythii the character PB (body length), PK (long head), JMT (distance muzzle tympanum), PM (long snout), JHM (distance nose to snout), JMTi (the distance from the eye to tympanum), JIN (distance inter nares), DM (eye diameter), Jio (inter-orbital distance), PKM (the length of the eyelids), PBR (length branchium) and PF (femur length). Variation in the morphology of a species is a response to changes in the physical environment where the species. With the differentiation and the high variation observed in all populations, it may be an indication that the occurrence of speciation. morphometric differentiation pattern Limonectes population of some areas. Population L. blythii between Harau and Sijunjung showed the highest differentiation $(p \geq 0.005) 10$ characters $(32.2 \%)$, followed by between population differentiation Harau with Malampah with as many as 8 characters $(25.8 \%)$ and among populations with Sijunjung show Malampah 7 ( 22:58\%). There was no significant difference on the PK (head head) of each population were observed, Limnonects blythii differentiated into two clusters, namely clusters and cluster Harau Sijunjung with Malampah on one sub-cluster shows the close genetic relationship between populations and 
Sijunjung Malampah compared with Harau population. However, the result of this research, it could be recommended that $L$. blythii is one commodity exports and as livelihoods, conservation efforts are needed to avoid the extinction.

\section{References}

[1] P. van Dijk Paul and D. Iskandar, "Limnonectes blythii , Giant Asian River Frog," vol. 8235, 2015.

[2] J. Rowley et al., "Impending conservation crisis for Southeast Asian amphibians," Biol. Lett., 2010.

[3] D. T. Iskandar and W. R. Erdelen, "Conservation of amphibians and reptiles in Indonesia: issues and problems," Amphib. Reptil. Conserv., vol. 4, no. 1, pp. 60-87, 2006.

[4] R. F. Inger, B. L. Stuart, and D. T. Iskandar, "Systematics of a widespread Southeast Asian frog, Rana chalconota (Amphibia: Anura: Ranidae)," Zool. J. Linn. Soc., vol. 155, pp. 123-147, 2009.

[5] R. F. Inger, B. L. Stuart, and D. T. Iskandar, "Systematics of a widespread Southeast Asian frog, Rana chalconota ( Amphibia: Anura: Ranidae )," pp. 123147, 2009.

[6] N. Kurniawan et al., "Genetic Divergence and Evolutionary Relationship in Fejervarya cancrivora from Indonesia and Other Asian Countries Inferred from Allozyme and MtDNA Sequence Analyses," Zoolog. Sci., vol. 27, no. 3, pp. 222-233, 2010.

[7] M. M. R. Alam, Mohammad Shafiqu Kurabayashi, Atsushi Hayashi, Yoko Sano, Naomi Khan, T. Fujii, and M. Sumida, "Complete mitochondrial genomes and novel gene rearrangements in two dicroglossid frogs, Hoplobatrachus tigerinus and Euphlyctis hexadactylus, from Bangladesh," Genes Genet. Syst., vol. 85, no. 3, pp. 219-232, 2010.

[8] M. Wati and D. H. Tjong, "Studi Fenetik Katak Rana nicobariensis Stoliczka , 1870 ( Ranidae ) di Pulau Siberut dan Daerah Dataran Rendah Sumatera Barat," vol. 1870, 2013.

[9] M. Hasan et al., "Genetic divergences of South and Southeast Asian frogs: A case study of several taxa based on $16 \mathrm{~S}$ ribosomal RNA gene data with notes on the generic name Fejervarya," Turkish J. Zool., vol. 38, no. 4, pp. 389-411, 2014.

[10] M. Matsui, D. M. Belabut, and N. Ahmad, "Two new species of fanged frogs from Peninsular Malaysia (Anura: Dicroglossidae)," Zootaxa, vol. 3881, no. 1, pp. 75-93, 2014.

[11] H. Addaha, D. Hon, and W. Novarino, "Variasi Morfologi Katak Pohon Bergaris Polypedates leucomystax Gravenhorst , 1829 ( Anura; Rhacophoridae ) di Sumatera Barat Morfological Variation of Striped Tree Frog Polypedates leucomystax Gravenhorst ， 1829 ( Anura ; Rhacophoridae ) in West Sumatera," vol. 4, no. 3, pp. 348-354, 1829.

[12] I. Das and A. Haas, "A NEW SPECIES OF RHACOPHORUS ( ANURA : RHACOPHORIDAE ) FROM GUNUNG GADING , SARAWAK," vol. 53, no. 2, pp. 257-263, 2005.

[13] B. L. Stuart, R. F. Inger, and H. K. Voris, "High level of cryptic species diversity revealed by sympatric lineages of Southeast Asian forest frogs," vol. 1887, no. June, pp. 470-474, 2006.

[14] D. S. McLeod, S. J. Horner, C. Husted, A. Barley, and D. Iskandar, "'Same-same, but different': An unusual new species of the Limnonectes kuhlii Complex from West Sumatra (Anura: Dicroglossidae)," Zootaxa, vol. 64, no. 2883, pp. 52-64, 2011. 